\title{
Identification of Asperger's from healthy individuals: Using a graph theoretical approach on the task-free fMRI data
}

\author{
Jahangir Mobarezpour ${ }^{1}$, Reza Khosrowabadi ${ }^{2 *}$ (ID, Reza Ghaderi ${ }^{3}$, Keivan Navi ${ }^{4}$ \\ 1. PhD Student in Cognitive Modeling, Institute for Cognitive and Brain Sciences, Shahid Beheshti University GC, Tehran, Iran \\ 2. Assistant Professor of Cognitive Modeling, Institute for Cognitive and Brain Sciences, Shahid Beheshti University GC, Tehran, Iran \\ 3. Associate Professor of Cognitive Modeling, Institute for Cognitive and Brain Sciences, Shahid Beheshti University GC, Tehran, Iran \\ 4. Professor of Cognitive Modeling, Institute for Cognitive and Brain Sciences, Shahid Beheshti University GC, Tehran, Iran
}

Recieved: 10 Jun. 2018

Revised: 10 Dec. 2018

Accepted: 31 Dec. 2018

Keywords

Asperger's syndrome

Functional magnetic resonance imaging (fMRI)

Graph theory

Corresponding author

Alireza Moradi, Institute for Cognitive Sciences Studies, Chamran Blvd, Pazhouheshkadeh Blvd, Safir Omid Blvd, Edalat Sq, 4th Phase, Pardis, Tehran, Iran

Email: R_khosroabadi@sbu.ac.ir

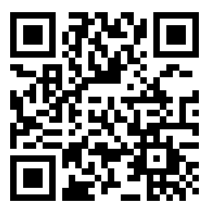

\section{Abstract}

Introduction: Asperger's syndrome is generally known as a neurodevelopmental disorder. The main features of this syndrome are the lack of social interaction, non-verbal communication, unusual repetitive behavior, restricted interests, and may have an inherent talent such as mathematics, music, etc. Nonetheless, their brain structural and functional variations as compared to healthy individuals require to be well understood. Methods: This study intends to identify differences of the task-free fMRI data in Asperger's syndrome as compared to healthy individuals using the graph-theoretical approach. In this approach, graph local and global measures are calculated from the functional network, which estimated through taking the correlation between activities in different parts of the brain. Subsequently, the differential pattern of local and global measures in Asperger's syndrome as compared to healthy control group is investigated. Two groups of the subjects are matched in terms of age, gender, handedness, and IQ scores.

Results: Results revealed the significant differences in local measures at temporal, amygdala, thalamus, and heschl regions. Classification of the tf-fMRI data based on the identified measures shows an accuracy of $84 \%$ to discriminate Asperger's individuals from the healthy group.

Conclusion: Accordingly, local measures extracted from the graph of the task-free functional connectivity network have a good potential for screening of Asperger's syndrome that can be used as an automatically-diagnosed method of this disorder. 
D)

\title{
تشخيص افراد اسِر گر از سالم با به كار تيرى نظريه تر اف بر روى تصاوير عملكردى مغز به روش تشديد مغناطيسى
}

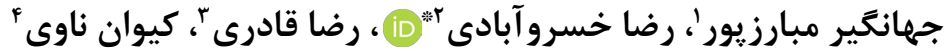

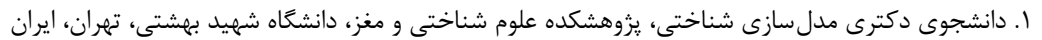

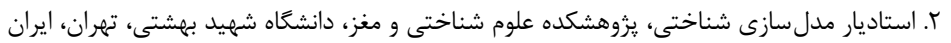

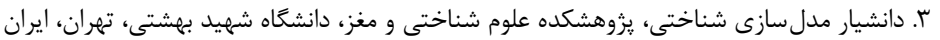

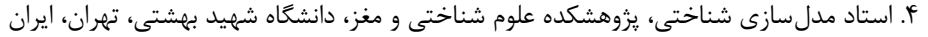

\section{ars}

مقدمهذ: سندروم اسيركر به عنوان يك اختلال عصب تحولى شناخته مىشود و داراى نشانه هايى از قبيل عدم تعاملات جتماعى، عدم ارتباط غيركلامى، بازه محدود علايق، رفتارهاى غير عادى و تكرارى مىباشد. افراد آسيركر معمولا داراى قريحه ذاتى در يك زمينه مانند موسيقى، رياضى يا غيره هستند. هر جند هنوز تفاوتهاى ساختارى و عملكردى مغز

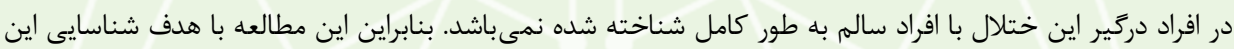
تفاوت ها با استفاده از تحليل تصاوير عملكردى مغز به روش تشديد مغناطيسى در حالت استراحت بر اساس نظريه كراف

روش كار: اين تحليل بر اساس محاسبه ارتباط ميزان ارتباط عملكردى نواحى مختلف مغز بر پايه شباهت عملكردى آنها صورت كرفت. ميزان اختلاف اين ارتباطها در سطح محلى و رفتار كلى مغز بين دو كروه اسيرگر و سالم كه از لحاظ سن، جنسيت، راست/جٍٍ دست بودن و ميزان بهره هوشى همكن انتحاب شده بودند، مورد مطالعه قرار كرفت. يافته ها: نتايج نشان داد كه اين تفاوتها بيشتر به صورت محلى در نواحى كيجكاهى، آميكدال، تالاموس و هلش قابل مشاهده بود. به علاوه استفاده از روش هاى دستهبندى بر روى تفاوت هاى مشاهده شده در شبكه عملكردى مغز نشان داد

$$
\text { كه مى توان افراد اسيرگر را با دقت AF درصد از افراد سالم شناسايى نمود. }
$$

نتيجه كَيرى: اين مطالعه نشان مى دهد، مشخصههاى محلى شبكه عملكردى مغز در حالت استراحت مى تواند ابزار مناسبى براى نمايش تفاوتهاى موجود بين دو كروه اسِركر و سالم باشد كه مىتوان از آن در شناسايى خودكار اين

$$
\text { اختلال بهره برد. }
$$

دريافت: •r/r/r/r/r

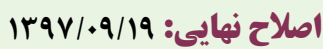

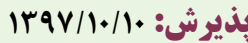
وازههاى كليلى اسيركر تصوير بردارى تشديد مغناطيسى نظريه كراف

نويسنله مسئول رضا خسروآبادى، استاديار مدلسازى شناختى، يُوهشكده علوم شناختى و مغز، دانشگاه شهيد بهشتى، تهران، ايران

ايميل:khosroabadi@sbu.ac.ir

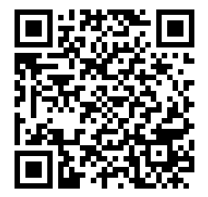

dol doi.org/10.30699/icss.21.3.74

مقدمه

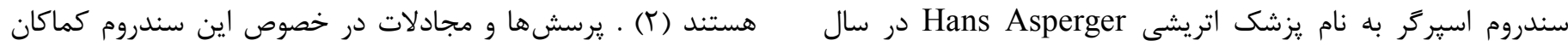
ادامه داشته، زيرا برخى از محققين معتقدند افراد درگير اين سندروم 19fF صرفا داراى اختلاف در گرايش، روش و رفتار هستند لذا نمى توان از آن عدم ارتباط غير كلامى، عدم ارتباط و معاشرت با همسالان خود بودند به عنوان يك ناتوانى كه مى بايست مورد درمان قرار گيرد، ياد كرد (ז، (1). اين سندروم با طيف بيمارى اوتيسهم تفاوت دارد زيرا اين نوع افراد f). با اين وجود از سال سا •r در نسخه ينجم راهنماى تشخيصى و تكامل زبانى و شناختى نسبتا طبيعى دارند و داراى بهره هوشى طبيعى 


\section{دوش كار}

شركت كنندكان اين مطالعه شامل سا نفر با سندروم اسيرگر (r نفر

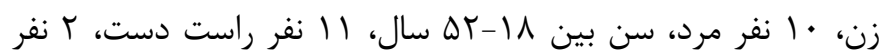

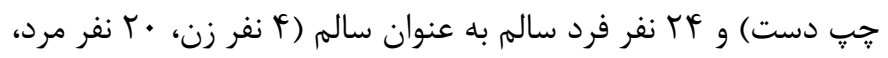
سن بين |Y-Y

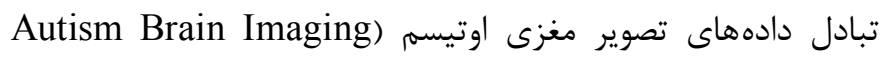
(Data Exchange Ludwig-Maximilians اين مطالعه اسكن fMRI افراد شركت كننده در حالت استراحت به صورت جشمم بسته صورت گرفته است. معيار شناسايى و انتخاب افراد با سندروم اسيرگر و سالم براى اين مطالعه اين بود كه مى بايست بهره

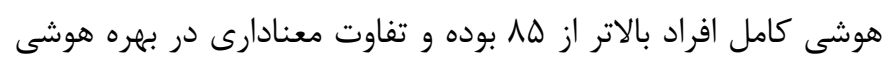
كلامى بين دو گروه وجود نداشته باشد. معيار شناسايى افراد اسپر

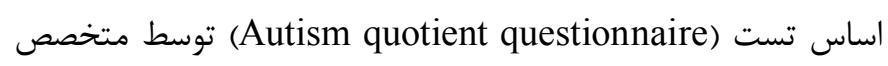
اوتيسم صورت گرفت كه عددى برابر يا بالاتر از IV معرف افراد مبتلا

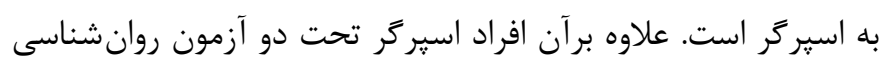
Questionnaire to) و (Freiburg personality inventory) نstimate autistic symptoms شخصيتى و اجتماعى اين نوع افراد مورد ارزيابى قرار مى داد. در اين مطالعه از بهره هوشى كامل به عنوان يارامتر سايكوفيزيك شناختى براى مقايسه دو گروه استفاده شده است (جدول (1). همانطور كه نتايج نشان مى دهد تفاوت معنادارى بين دو گروه از نظر سن و بهره هوشى كامل وجود ندارد (ه •|•>P). اين نتيجه تاييدى براى شواهد قبلى است كه مبتلايان به اسيرگر را داراى بهره هوشى طبيعى مى داند (r). تصويربردارى: همه دادههاى تصويرى در ميدان مغناطيسى مَ تسلا بدست آمدهاند. از هر شركت كننده يك تصور ساختارى و يك تصوير عملكردى در حالت استراحت در يك جلسه گرفته شد. تصوير ساختارى با قدرت تفكيك بالا با استفاده از روش MPRAGE 9 TII=1800/3.06/900 msec TA=3:41 min EPI و 1 1 1 mm³ ᄉ. "TR/TE=3000/30 msec، TA=6:06 min)

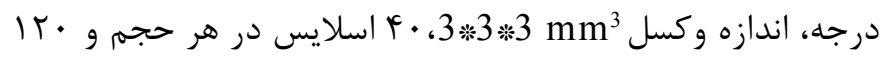
بار اندازه گيرى) به نحوى كه شركت كننده جشمى خود را بسته و به هيج جيز فكر نمى كند، به دست آمده است.
آمارى اختلالات روانى The Diagnostic and Statistical Manual of Mental Disorders, Fifth Edition (DSM-5)) انواع بيمارى اوتيسم با يك نمره خاص از نظر شدت شناخته مى شود (ه).

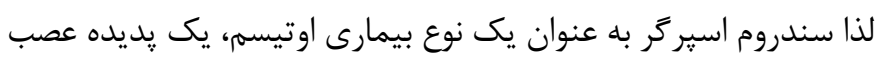

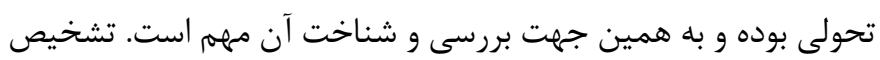

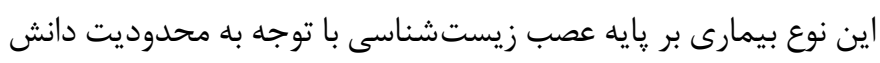

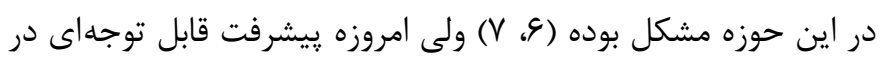
تشخيص نشانه هاى بيمارى اوتيسم بدست آمده كه از ميان آنها مى توان به روش غربال زرى خود كار اشاره كرد كه با توجه به سرعت، عملى بودن و سهولت در فرآيند ارزيابى يك روش مفيد به نظر مىرسد (1)، 9). در روش غربال اختلاف در اين شاخصها است كه باعث تفكيك افراد به بيمار و سالم مىشود. از تكنيكهاى تصويربردارى عصبى مى توان به عنوان روش احس غير تهاجمى و نسبتا قابل اعتماد براى غربال گرى خود كار استفاده كرد.

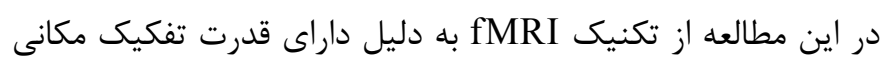
بالاتر از روش ثبت امواج مغزى، عليرغم يايينتر بودن قدرت تفكيك آن

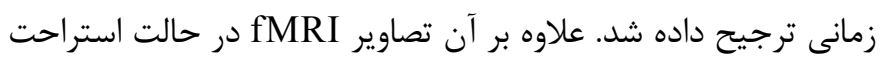
بدست آمده است، علت استفاده از اين حالت كاهش تغييريذيرى در تكرار روش هاى انجام يك وظيفه به هنغام تصويربردارى است (• (1r (1). همجنين روش انجام يك وظيفه صرفا بخش خاصى از مغز را فعال مى كند ولى هدف اين مطالعه بررسى تمام مغز به صورت يكيار جه بود. در اغلب يزوهش ها عنوان مىشود كه ارتباطهاى عملكردى كه از حالت استراحت مغز استخراج مىشود بازتاب عملكرد سازمان مغز از نظر روش هاى او شناختى مى باشد (ب ا ). تحليل هاى مختلفى با استفاده از

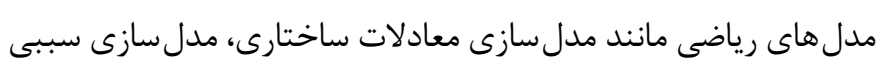
يويا (Dynamic causal modelling) و عليت كرانجر (Granger) (causality كار مىرود، ولى رويكرد نظريه گراف يكى از تحليل هاى قابل اعتماد و تكراريذير براى دادههاى شبكه ارتباطهاى عملكردى محسوب مى شود

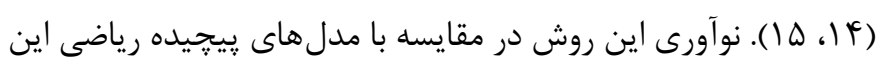
است كه از نظر محاسباتى ساده و نياز به كاهش ابعاد داده ها و دانش قبلى ندارد. به علاوه قابليت رصد يارامترهاى محلى و كلى مغز را به

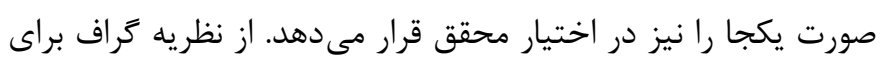
مطالعه ساير بيمارى ها مانند آلزايمر و اسكيزوفرنى نيز استفاده مى شود. در اين مطالعه علاوه بر معرفى روشى براى شناسايى مبتلايان اسيرگر، تفاوت ارتباط عملكردى در شبكه مغزى اين نوع افراد با افراد سالم مورد بررسى قرار زرفت. 
جدول ا. اطلاعات مربوط به سن و بهره هوشى كامل گروههاى مورد مطالعه

\begin{tabular}{|c|c|c|c|c|c|c|}
\hline \multicolumn{2}{|c|}{ مقايسات آمارى } & \multicolumn{2}{|r|}{ تعداد=آسر } & \multicolumn{2}{|r|}{ تعداد= سالم } & \multirow{2}{*}{ كروهها } \\
\hline P-value & t-value & 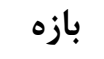 & ميانغين土 انحراف استاندارد & 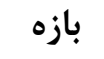 & ميانغين土 انحراف استاندارد & \\
\hline$\cdot \mid 94$ & $\cdot / F V \varepsilon$ & $\mid \Lambda-\Delta T$ & 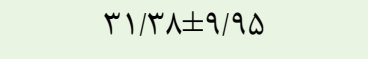 & $r I-r \Lambda$ & $r \cdot \pm V / \Delta F$ & سن \\
\hline$\cdot / 49$ & $1 / \cdot v$ & - & $\|f / \mid \Delta \pm\| / \Gamma q$ & - & $11 \cdot 19 \mathrm{~V} \pm \Lambda / \mathrm{V}$ & بهره هوشى \\
\hline
\end{tabular}

زمانى بين هر زوج نواحى با استفاده از ضرايب رابطه پيرسون تشكيل

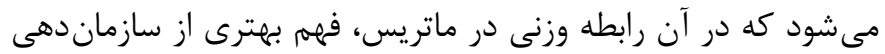
مغز در شبكه بدست مى دهد. بنابراين شبكه عملكردى مغز به صورت ماتريس متقارن وزنى و بدون جهت از مقدار مطلق ضرايب پِيرسون كه دهائ

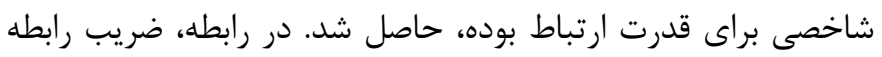

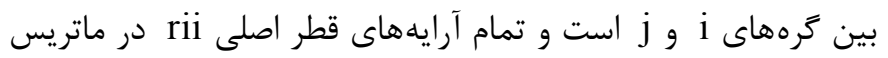
صفر منظور مى شود.

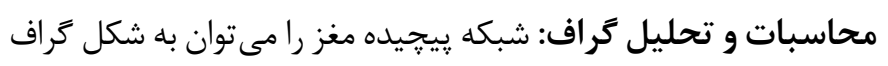

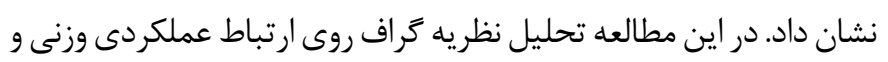

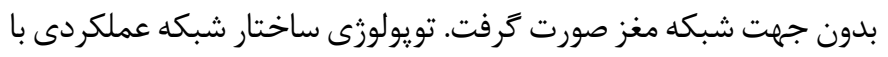
شاخصهاى دنياى كوجك، ضريب خوشهبندى سراسرى و بازده سراسرى تعيين شد. درجه و مركزيت گره، نزديكى، بازده محلى، ميان گيرى و

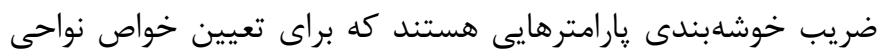

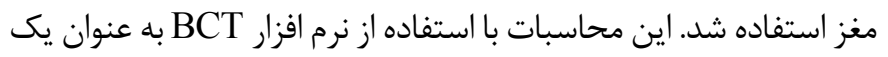

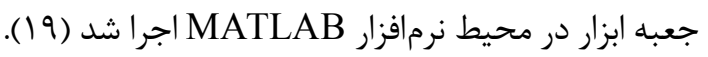

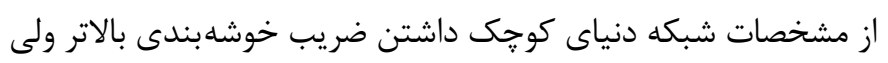

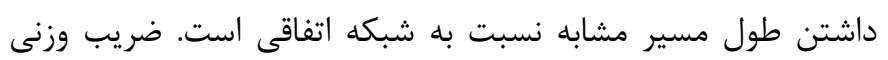

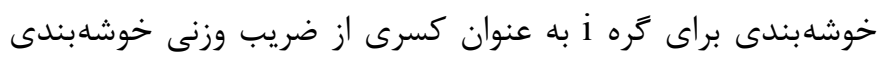
$C_{i}^{w}=\frac{\sum_{j, h \in N}\left(w_{i j} w_{j h} w_{i h}\right)^{1 / 3}}{k_{i}\left(k_{i}-1\right)}$ شبكه تعريف مى شود. كه در آن N تعداد گرهها در شبكه و Ki درجه هر گره است. بنابراين ضريب وزنى خوشهبندى شبكه با رابطه زير بيان مىشود.

$C_{i}^{w}=\frac{1}{N} \sum_{i=1}^{N} C_{i}^{w}$

طول مسير بين كرههاى i j i برابر با مجموع تمام يال ها است كه با
يردازش استاندارد روى تصاوير خام با استفاده از نرمافزارهاى FSL (ع)

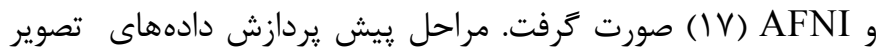
عملكردى در حالت استراحت شامل ( () حذف ه حجم اوليه (Y) تصحيح

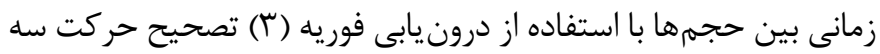

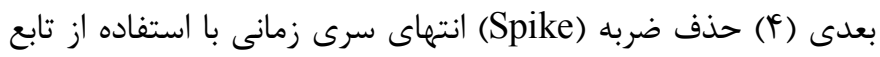

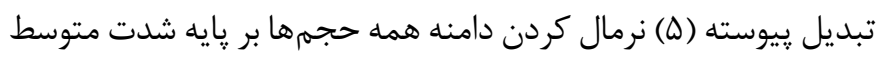

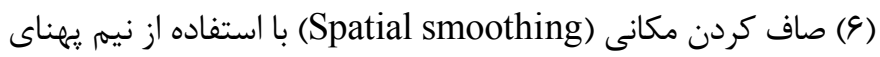
فيلتر كرنل كوسى با ماكزيمه \& ميلىمتر (V) فيلترينَ زمانى مانى ميان

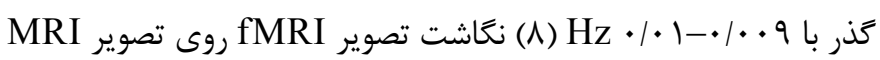

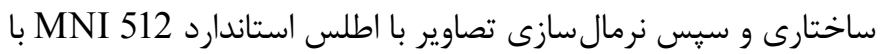

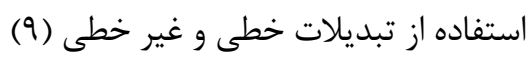

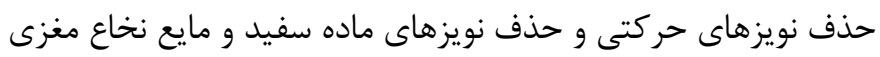

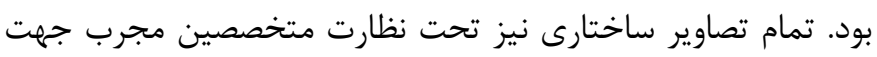

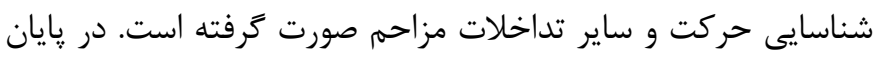

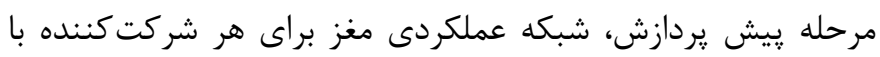

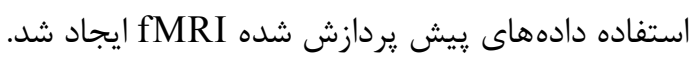

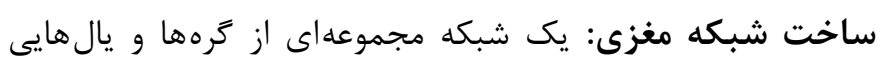

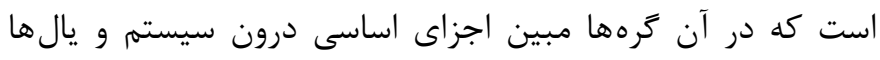

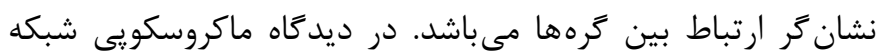
مغز، كرهها به عنوان نواحى تفكيك شده ساختارى يا عملكردى تعريف

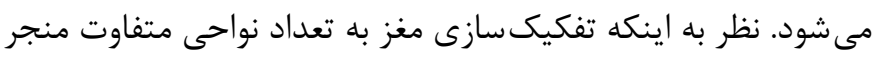
به نتايج مختلف تحليل شبكه مغز مى شود در اين مطالعه از نمونه

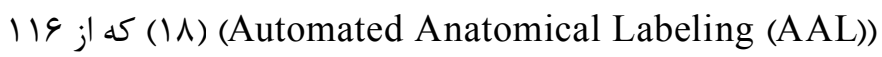
ناحيه قشرى و زير قشرى تشكيل شده، استفاده شد. ارتباط عملكردى در شبكه مغز به مفهوم ارتباط زمانى سيخنال هاى (

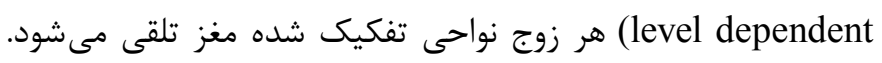

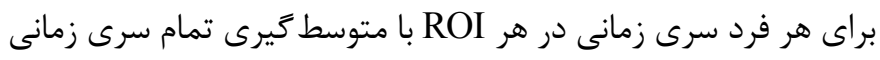

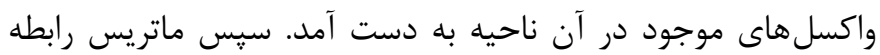


$E_{l o c}(G)=\frac{1}{N} \sum_{i=1}^{N} E_{g l o b}\left(G_{i}\right)$

كه در آن G به معنى كراف ناحيهاى مشخص از شبكه مغزى است. در

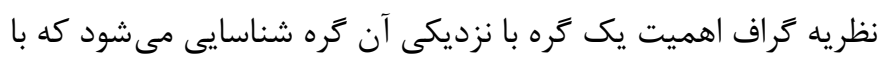

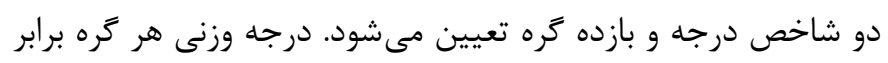

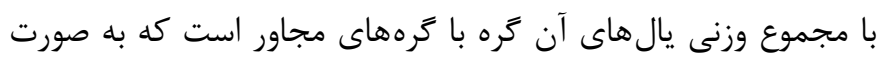

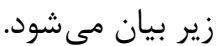

$D_{i}=\sum_{j=1}^{N} w_{i j}$

كه در آن Wij يال وزنى بين دو كره i و زاست. بازده كره به مفهوم توانايى

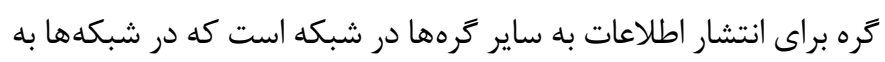

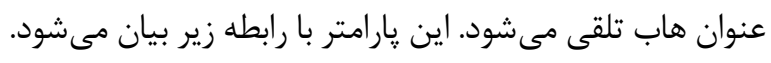

$E_{i}=\frac{1}{(N-1)} \sum_{i \neq j=1}^{N} \frac{1}{L_{i j}}$

شاخص ميان كيرى به عنوان كسرى از كوتاهترين مسيرها در شبكه

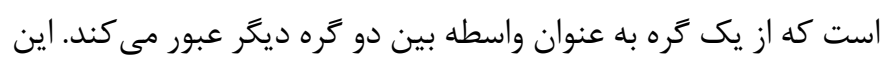
معيار با رابطه زير تعريف مى شود.

$b_{i}=\frac{1}{(N-1)(N-2)} \sum_{i \neq j, h \neq i, h \neq j} \frac{P_{h}}{P}$

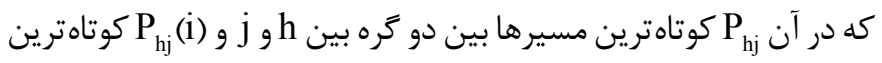

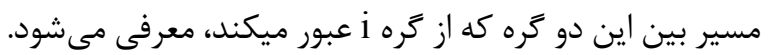

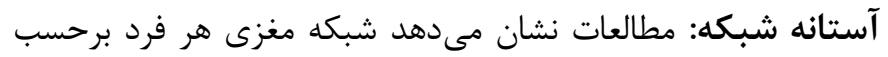

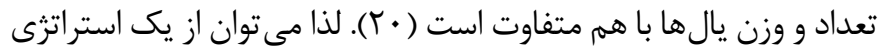

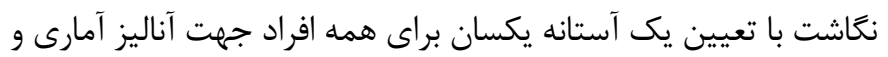

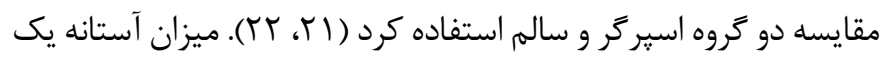

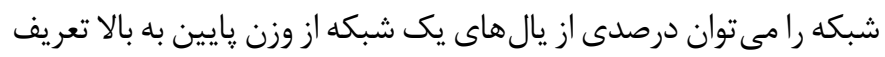

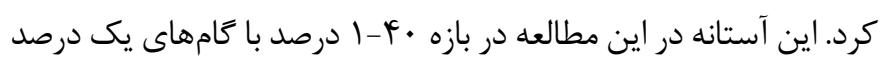

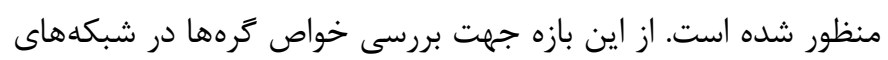

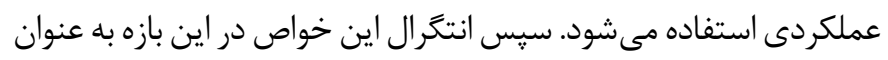
شاخصى براى مقايسه سنجش هاى گرهها استفاده شده است (rT).

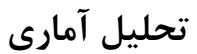
تفاوت بين دو كروه بر اساس شاخصهاى سراسرى شبكه مغزى: براى 1/w محاسبه مى شود و نشان نحوى كه اين مسير از يك گره بيش از يك مرتبه عبور نكند. سيس إس

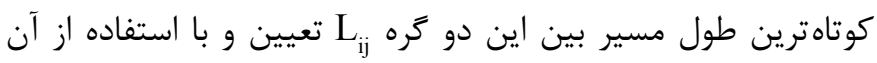

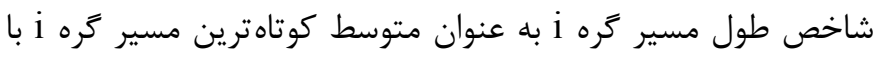
ساير گرهها با رابطه زير تعريف مى شود.

$L_{i}=\frac{1}{(N-1)} \sum_{i \neq j=1}^{N} L_{i j}$

شاخص طول مسير وزنى شبكه معيارى براى گسترش اطلاعات به صورت موازى در شبكه است كه مى تواند اشكال عدم اتصال در بخشى لشى

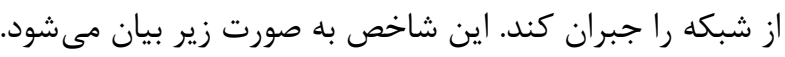

$$
L_{n e t}^{w}=\frac{1}{\frac{1}{(N-1)} \sum_{i=1}^{N} \sum_{i \neq j=1}^{N} \frac{1}{L_{i j}}}
$$

در نهايت خاصيت دنياى كوجى كه مبين ضريب خوشهبندى بالا و طول مسير كوتاه است در مقايسه با شبكه اتفاقى با رابطه زير تعيين

$$
S W^{w}=\frac{C_{\text {net }}^{w} / C_{\text {rand }}^{w}}{L_{\text {net }}^{w} / L_{\text {rand }}^{w}}
$$

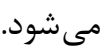

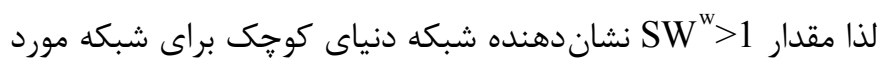

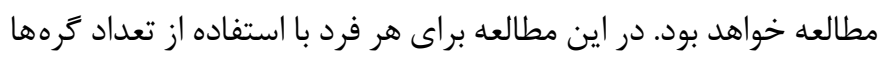

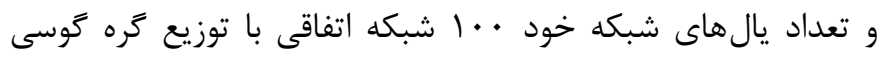
ايجاد و سيس ضريب خوشهبندى و طول مسير شبكه اتفاقى براى هر فرد از متوسط گيرى . . إدبكه اتفاقى بدست آمده است.

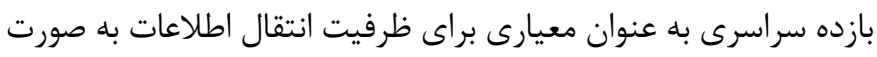

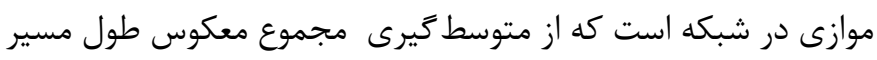
هر كَره به دست مى دئ آيد.

$E_{g l o b}(G)=\frac{1}{N(N-1)} \sum_{1 \leq i, j \leq N, i \neq j} \frac{1}{L_{i j}}$

كه در آن G به معنى كراف شبكه مغزى، N تعداد گرهها در شبكه و

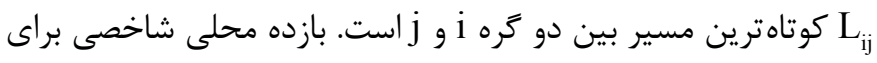
ظرفيت انتقال اطلاعات در سطح ناحيهاى از مغز مىباشد كه با رابطه

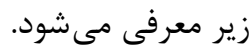


بين دو گروه اسير گر و سالم با استفاده از t-test براى دو گروه مستقل براى شاخص هاى گره انجام شد. مقايسه صحيح دو گروه با تعيين نرخ خطاى مثبت كه بر حسب اطمينان ه • P محاسبه شده، صورت گرفت. همه تحليل هاى آمارى با استفاده از نرمافزار MATLAB انجام گرفت. شكل ا طراحى اين مطالعه را تا مرحله تحليل آمارى نشان مى دهد. طبقهبندى: از شاخص هاى معنادار گره در شبكه عملكردى مغز مى توان به عنوان ويزَّى ها براى طبقهبندى افراد اسيرگر و سالم استفاده كرد. در اين مطالعه از سه دسته كننده براى مقايسه عملكرد آنها و انتخاب روش برتر به كار گرفته شد. اين سه روش SVM
مقايسه بازده سراسرى و محلى شبكه عملكردى مغز بايد اثر متغيرهاى هميراش مانند سن، بهره هوشى كامل، جֶٍ يا راست دست بودن در تفاوت شكل ساختار مغزى بين دو گروه با به كارگيرى مدل خطى عمومى حذف شود ولى همانطور كه در جدول ا نشان ميدهد تفاوت معنادارى براى متغيرهاى سن و بهره هوشى كامل بين دو گروه اسيركر و سالم مشاهده نشد (ه •/P<). لذا شاخص هاى انتخرال شده بازده سراسرى و محلى در بازه تعريف شده آستانه صرفا با حذف متغير گֶ يا راست دست بودن براى مقايسه دو گروه بكار مى گيرد. تفاوت بين دو گروه بر اساس شاخصهاى گره در شبكه مغزى: مقايسه

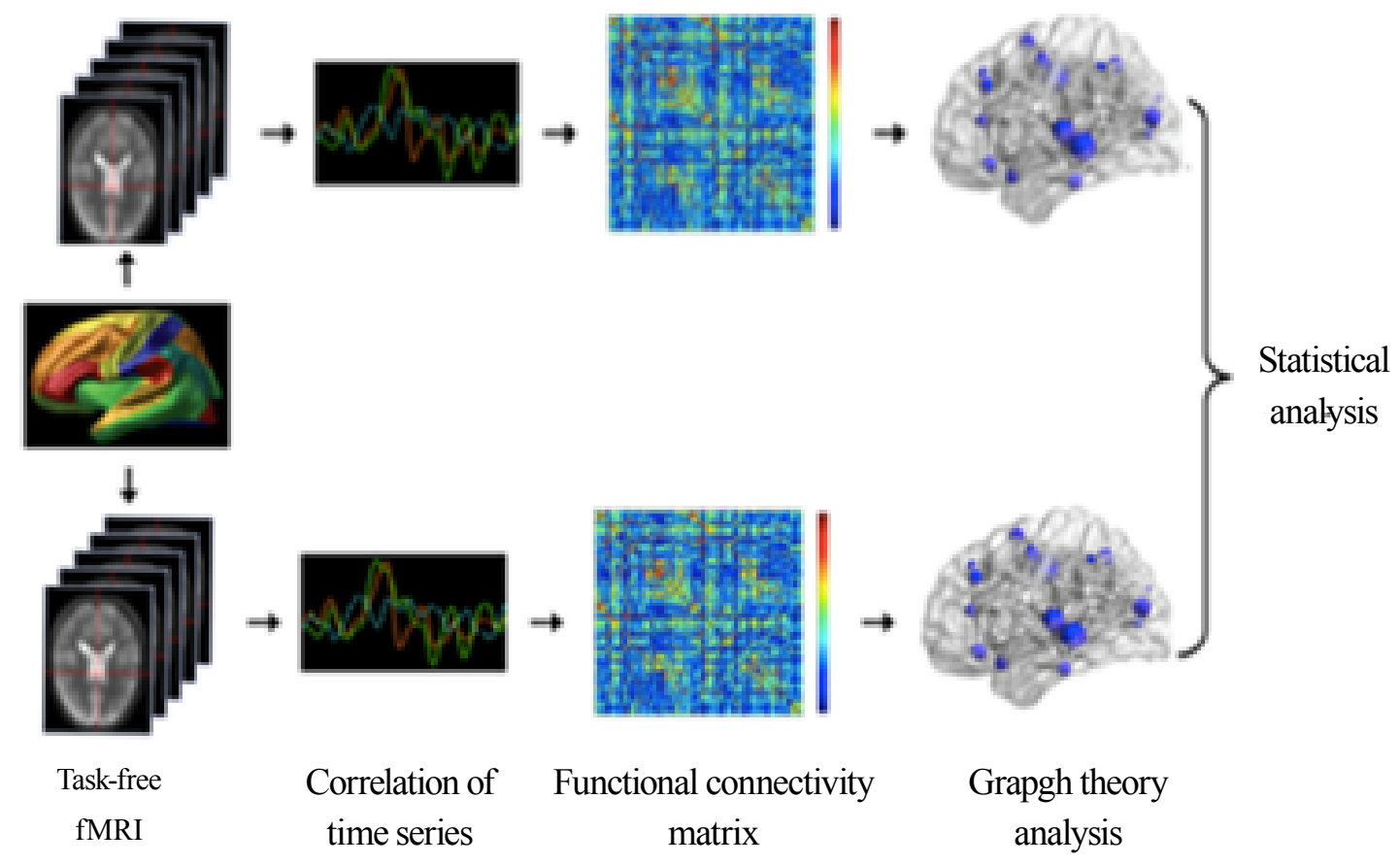

شكل (. طراحى مدل مطالعه تا مرحله تحليل آمارى (با استفاده از شكل مرجع ؟F با مجوز مولف)

(YV) هستند. براى سنجش دقت ميى توان اين طبقهبندى را مورد آزمون با توجه به تعداد افراد مقدار K=5 منظور شد. شكل r طراحى اين مطالعه

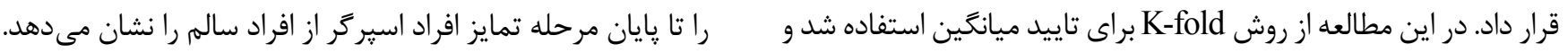

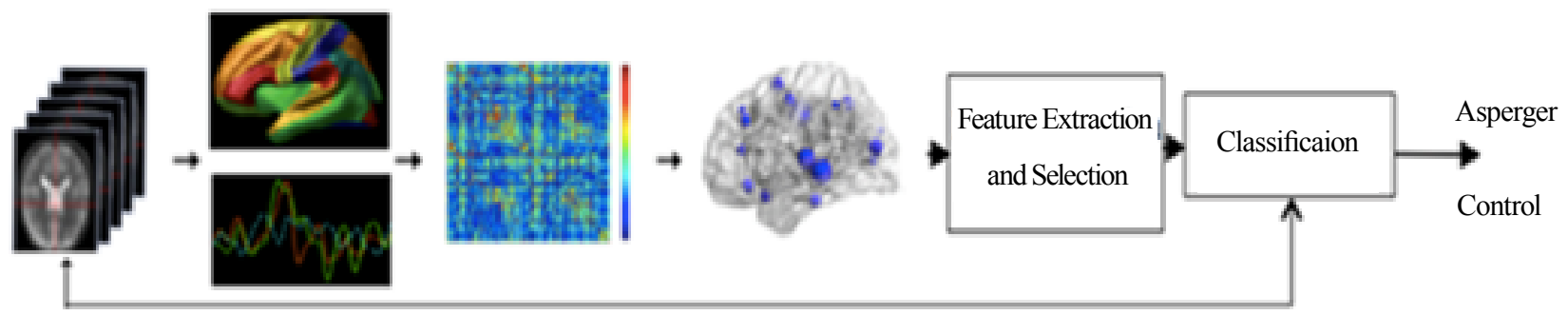

شكل r. طراحى مدل مطالعه تا مرحله پِايانى تمايز افراد اسيرگر و كنترل 
يافته ها

r). مركزيت گره بين دو كروه داراى اختلاف معنادار بود و لذا به عنوان

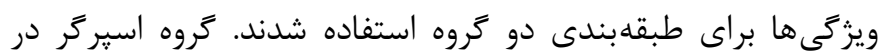
مقايسه با كروه سالم در نيم كره جٍ مغز در جهمار ناحيه و در نيم كره راست مغز در يك ناحيه تفاوت داشت (شكل \&). شاخص نزديكى در

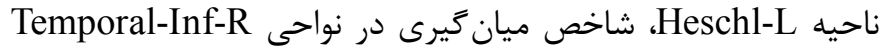
و و شاخص مركزيت كره در نواحى Amyalamus-L و و Heschl-L بين دو گروه داراى اختلاف بود (شكل \&).
مقايسه بين دو گروه اسيركر و سالم تفاوت معنادارى از نظر شاخص سراسرى در ارتباط عملكردى نشان نداد. اين مقايسه با استفاده از

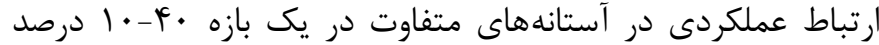
يالهاى شبكه عملكردى مغز صورت گرفته بود. گروه اسيرگر مقدار بزر گترى براى بازده عمومى، مقدار بزر كترى براى ضريب خوشهبندى سراسرى و مقدار كوجكترى براى خاصيت دنياى كوجك نسبت به كروه سالم نشان داد، ولى اين تفاوتها از نظر آمارى معنادار نبودند (شكل

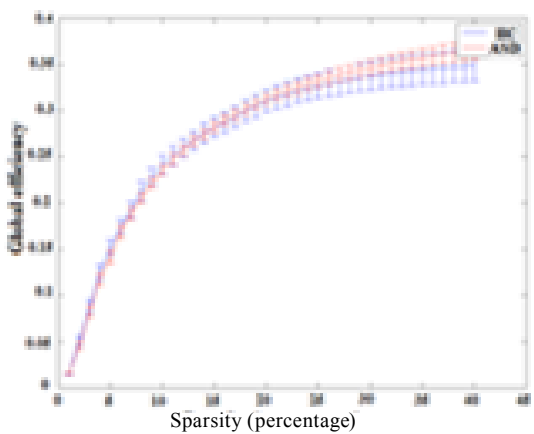

(a)

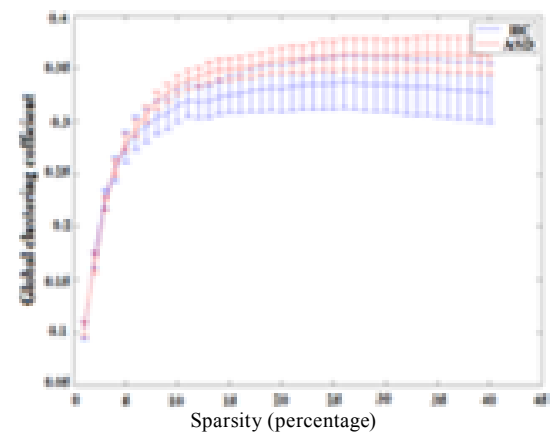

(b)

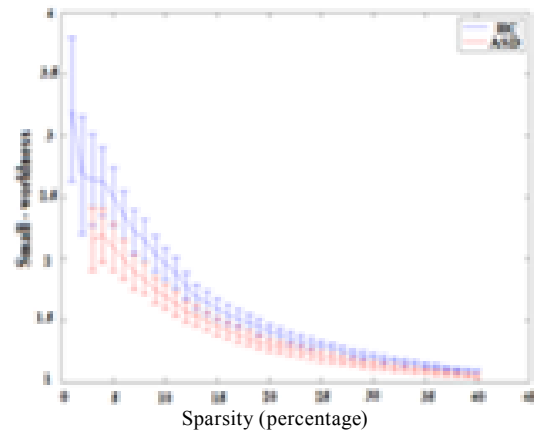

(c)

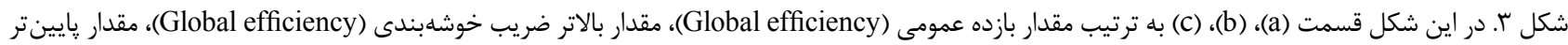

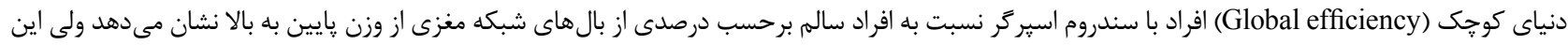

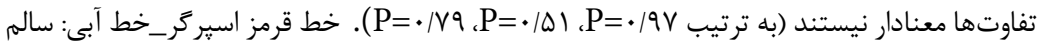
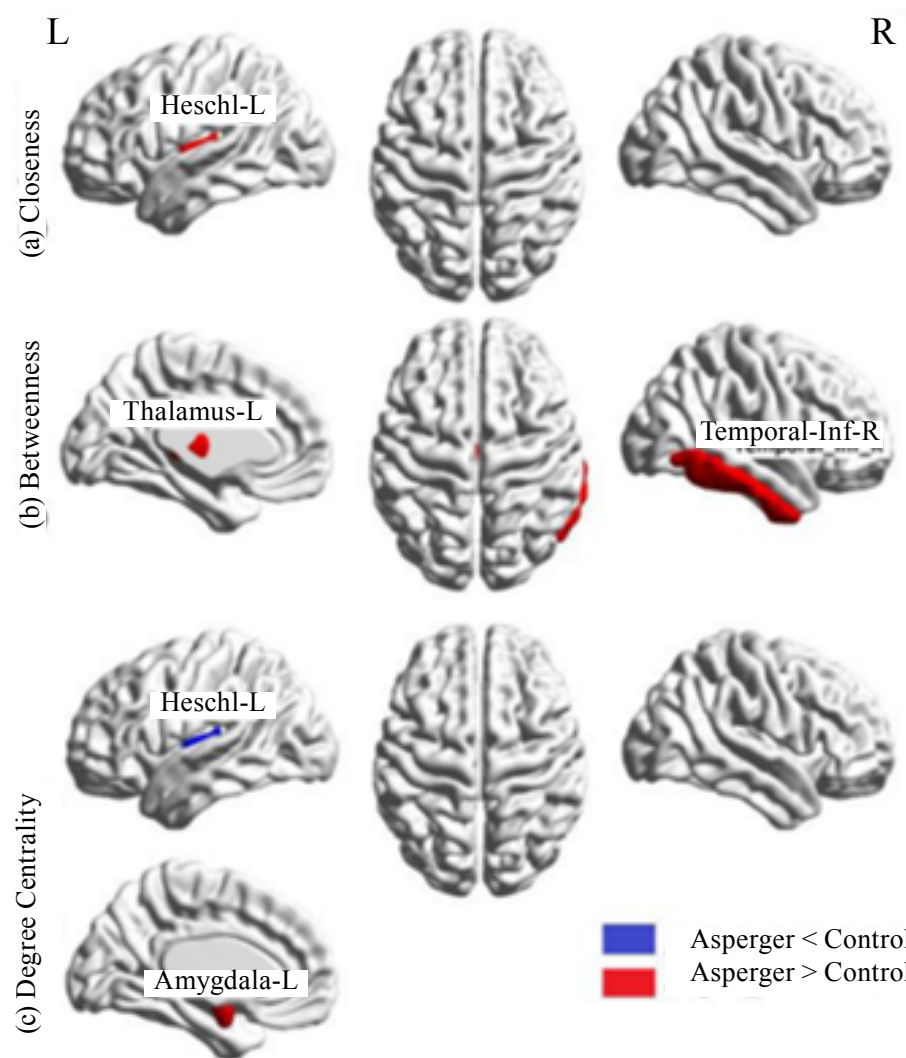

Brain Net Viewer شكل f. نمايش تفاوت نواحى مختلف مغز بين افراد اسير كر و كنترل با استفاده از نرمافزار 
مطالعه، جهت اطمينان از آموزش غير ايستا داده براى دسته كنندهها و رسيدن به دقت واقعى ل مرتبه به ترتيب هر بار ل نفر به صورت اتفاقى به

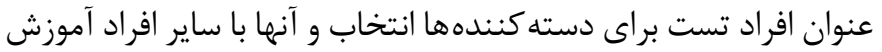
مىبينند و سيس ميانگين دقت و انحراف از استاندارد طبقهبندى تعيين شد. جدول r نتايج به دست آمده براى سه دسته كننده استفاده شده و و SVM ،NN
تمايز افراد اسيرگر با افراد سالم بر اساس شاخص گره ارتباط عملكردى: بر اساس ارتباط عملكردى در 11 إناحيه تفكيك شده مغز، ه ناحيه از نظر شاخص هاى نزديكى گره، ميان گيرى گره و مركزيت كره بين دو زروه اختلاف وجود داشت. لذا به عنوان ويزگى ها براى طبقهبندى استفاده شد (جدول r). نظر به استفاده روش K-fold cross validation

جدول r. نتايج دقت روشهاى دستهبندى مختلف استفاده شده بر حسب نوع و تعداد ويزگى ها

\begin{tabular}{|c|c|c|c|c|}
\hline ناييف بيز & نزديكترين همسايه & ماشين بردار يشتيبان & & كلاسهبند \\
\hline \multicolumn{3}{|c|}{ ميانگين ذانحر اف استاندارد } & تعداد مولفه & مولفه مورد نظر \\
\hline$\cdot / 9 \cdot \pm \cdot / 49$ & $\cdot / V I \pm \cdot / T r$ & $\cdot / \varepsilon \psi \pm \cdot / T \Delta$ & 1 & مركزيت بر اساس درجه \\
\hline$\cdot / V \vee \pm \cdot / 19$ & $\cdot / V T \pm \cdot / r \Delta$ & $\cdot \mid 9 \Lambda \pm \cdot / 1 \mathrm{~F}$ & r & مركزيت بر اساس ميزان بينابينى \\
\hline$\cdot / V \Delta \pm \cdot / 1 \Lambda$ & $\cdot 19 \Delta \pm \cdot 119$ & $\cdot / V F \pm \cdot / r$ & r & مركزيت بر اساس نزديكى \\
\hline$\cdot / V \wedge \pm \cdot / / r$ & $\cdot / \vee \wedge \pm \cdot / 19$ & $\cdot|\Lambda F \pm \cdot /|$. & $\Delta$ & كليه پارامترهاى بالا \\
\hline
\end{tabular}

تفاوت معنادار بين دو گروه بود. بر اساس نتايج به دست آمده تفاوت معنادارى از نظر شاخص سراسرى بين دو گروه مشاهده نشد، ولى از نظر شاخص هاى محلى از قبيل درجه و بينابينى متعلق به گرهها تفاوت معنادارى مشاهده شد كه به عنوان ابزارى براى تمايز دو گروه استفاده

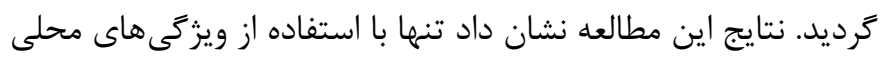
گراف مى توان با دقت NF درصد افراد با سندرم اسيرگر را از افراد سالم شناسايى كرد. اين نتايج مى تواند بيانگر اين موضوع باشد كه يارامترهاى كلى درخت عملكردى مغز در اختلال آسيرگَر به طور معنادار تغيير نمى يابند و تنها ميزان شاخ و برى آن است كه در نقاطى معين تغيير يافته و موجب اختلالات رفتارى شناختى مى گردد. اين موضوع مى تواند اميدوارى ما را براى درمان يذير بودن اين اختلال به طور شايسته اى بهبود بدهد. زيرا در صورت تغييرات كلى سيستم عملكردى تنظيمم

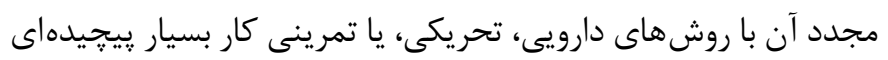
خواهد بود ولى تمركز بر كاهش يا افزايش فعاليتهاى محلى امرى

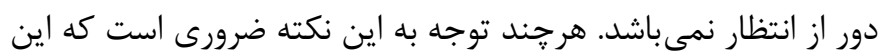
مطالعه از محدوديتهايى برخوردار بوده است، به طور مثال، تحليل

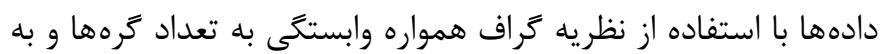
تعبيرى به قدرت تفكيك مدل دارد. لذا در اين مدل با استفاده از مرجع
مطالعات زيادى در خصوص اختلالات رفتارى، شناختى و تغييرات ساختارى و عملكردى مغز در سندرم آسيرگر صورت يذيرفته است كه رفتارهاى تكرارى و وسواس گونه به همراه رفتارهاى ارتباطى و هيجانى_اجتماعى متفاوت، رشد غيرمنظم حركتى و زبان گشودن ديرتر از موعد، از بارزترين مشخصه هاى اين اختلال مىباشد. بى شك درك بهتر اين اختلال با بررسى تغييرات ساختارى و عملكردى مغز در اين اختلال ميسر خواهد شد كه شواهدى همجون كاهش ماده خاكسترى در قسمتهاى متعدد از قبيل قشر پيشانى، آهيانهاى،

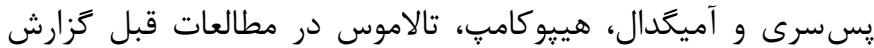
شده است (YY). علاوه بر تغييرات ساختارى، مواردى جون فعاليتهاى غيرمعمول مخجه، قشر پيشانى و آهيانهاى نيز ززارش شدهاند كه به

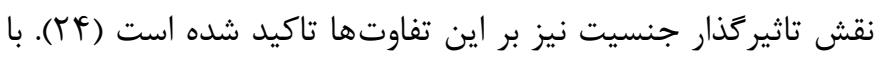
در نظر گرفتن اين نكته كه مغز سيستمى پيیجيده است و توجه به اين نكته كه رفتار هر يك اجزاى آن مىتواند بر رفتار كلى آن تاثير بحذارد ولى رفتار كلى جمع خطى رفتار اجزا نمى باشد (9 (1)، مطالعه حاضر صورت يذيرفت. در اين مطالعه از نظريه گراف براى تحليل تصاوير عملكردى مغز در حالت استراحت براى مقايسه شبكه هاى مغزى بين دو گروه اسيرگر و سالم استفاده شد كه نتايج حاصل حاكى از 


$$
\text { خودكار اين اختلال بهره برد. }
$$

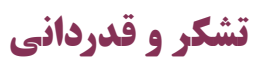

اين مقاله با حمايت يزوهشكده علوم شناختى و مغز دانشكاه شهيد

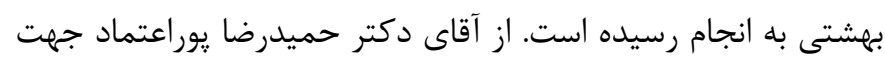

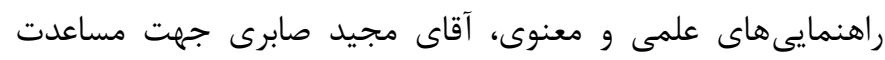

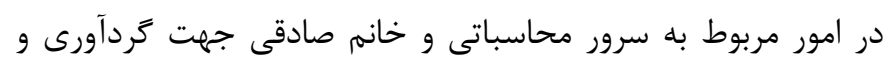
يردازش اوليه دادها، تشكر و قدردانى مى شود.

\section{References}

1. Frith U. Autism and Asperger's syndrome. Cambridge:Cambridge University Press;1991. pp. 37-92.

2. Mueller S, Keeser D, Samson AC, Kirsch V, Blautzik J, Grothe $\mathrm{M}$, et al. Convergent findings of altered functional and structural brain connectivity in individuals with high functioning autism: A multimodal MRI study. PloS One. 2013;8(6):e67329.

3. Clarke J, Van Amerom G. Asperger's syndrome: differences between parents' understanding and those diagnosed. Social Work in Health Care. 2008;46(3):85-106.

4. Baron-Cohen S. Is Asperger syndrome/high-functioning autism necessarily a disability?. Development and Psychopathology. 2000;12(3):489-500.

5. American Psychiatric Association. Diagnostic and Statistical Manual of Mental Disorders, 5th Edition:DSM-5®. Arlington VA:American Psychiatric Pub;2013.

6. Ecker C, Ginestet C, Feng Y, Johnston P, Lombardo MV, Lai $\mathrm{MC}$, et al. Brain surface anatomy in adults with autism: The relationship between surface area, cortical thickness, and autistic symptoms. JAMA Psychiatry. 2013;70(1):59-70.

7. Raff MC. Defining cell-surface antigenic markers for mouse T and B cells. Frontiers in Immunology. 2014;5:559.

8. Oller DK, Niyogi P, Gray S, Richards JA, Gilkerson J, Xu D, et al. Automated vocal analysis of naturalistic recordings from children with autism, language delay, and typical development. Proceedings of the National Academy of Sciences.

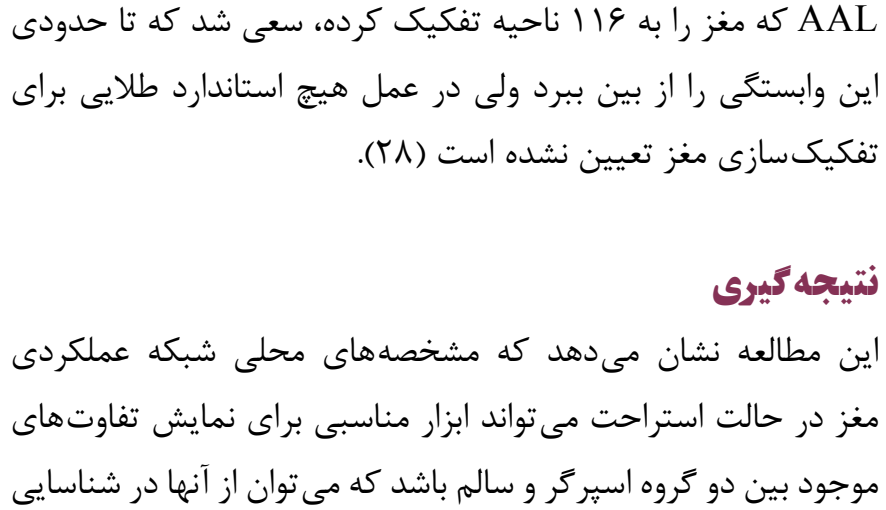

2010;107(30):13354-13359.

9. Hashemi J, Tepper M, Vallin Spina T, Esler A, Morellas V, Papanikolopoulos N,et al. Computer vision tools for low-cost and noninvasive measurement of autism-related behaviors in infants. Autism Research and Treatment. 2014;2014:935686 . 10. Smith SM, Beckmann CF, Ramnani N, Woolrich MW, Bannister PR, Jenkinson M,. Variability in fMRI: A re-examination of inter-session differences. Human Brain Mapping. 2005;24(3):248-257.

11. Zuo XN, Kelly C, Adelstein JS, Klein DF, Castellanos FX, Milham MP. Reliable intrinsic connectivity networks: Test-retest evaluation using ICA and dual regression approach. $\mathrm{Neu}$ roimage. 2010;49(3):2163-2177.

12. Kristo G, Rutten GJ, Raemaekers M, De Gelder B, Rombouts SA, Ramsey NF. Task and task-free FMRI reproducibility comparison for motor network identification. Human Brain Mapping. 2014;35(1):340-352.

13. Laird AR, Fox PM, Eickhoff SB, Turner JA, Ray KL, McKay DR, et al. Behavioral interpretations of intrinsic connectivity networks. Journal of Cognitive Neuroscience. 2011;23(12):4022-4037.

14. Bullmore E, Sporns O. Complex brain networks: Graph theoretical analysis of structural and functional systems. $\mathrm{Na}$ ture Reviews Neuroscience. 2009;10(3):186-198.

15. Tymofiyeva O, Ziv E, Barkovich AJ, Hess CP, Xu D. Brain without anatomy: Construction and comparison of ful- 
ly network-driven structural mri connectomes. PloS One. 2014;9(5):e96196.

16. Smith SM, Jenkinson M, Woolrich MW, Beckmann CF, Behrens TE, Johansen-Berg $\mathrm{H}$, et al. Advances in functional and structural MR image analysis and implementation as FSL. Neuroimage. 2004;23(Supl):208-219.

17. Cox RW. AFNI: Software for analysis and visualization of functional magnetic resonance neuroimages. Computers and Biomedical Research. 1996;29(3):162-173.

18. Tzourio-Mazoyer N, Landeau B, Papathanassiou D, Crivello F, Etard O, Delcroix N, Mazoyer B, Joliot M. Automated anatomical labeling of activations in SPM using a macroscopic anatomical parcellation of the MNI MRI single-subject brain. Neuroimage. 2002;15(1):273-289.

19. Rubinov M, Sporns O. Complex network measures of brain connectivity: Uses and interpretations. Neuroimage. 2010;52(3):1059-1069.

20. Wen W, Zhu W, He Y, Kochan NA, Reppermund S, Slavin MJ, et al. Discrete neuroanatomical networks are associated with specific cognitive abilities in old age. Journal of Neuroscience. 2011;31(4):1204-1212.

21. Bernhardt BC, Chen Z, He Y, Evans AC, Bernasconi N. Graph-theoretical analysis reveals disrupted small-world orga- nization of cortical thickness correlation networks in temporal lobe epilepsy. Cerebral Cortex. 2011;21(9):2147-2157.

22. Zhang Z, Liao W, Zuo XN, Wang Z, Yuan C, Jiao Q, et al. Resting-state brain organization revealed by functional covariance networks. PLoS One. 2011;6(12):e28817.

23. Gong G, He Y, Concha L, Lebel C, Gross DW, Evans AC, et al. Mapping anatomical connectivity patterns of human cerebral cortex using in vivo diffusion tensor imaging tractography. Cerebral Cortex. 2009;19(3):524-536.

24. Sadeghi M, Khosrowabadi R, Bakouie F, Mahdavi H, Eslahchi C, Pouretemad H. Screening of autism based on taskfree fMRI using graph theoretical approach. Psychiatry Research: Neuroimaging. 2017;263:48-56.

25. Cristianini N, Shawe-Taylor J. An introduction to support vector machines and other kernel-based learning methods. Cambridge:Cambridge University Press;2000.

26. Cover T, Hart P. Nearest neighbor pattern classification. IEEE Transactions on Information Theory. 1967;13(1):21-27.

27. Hand DJ, Yu K. Idiot's Bayes—not so stupid after all?. International Statistical Review. 2001;69(3):385-398.

28. Wig GS, Schlaggar BL, Petersen SE. Concepts and principles in the analysis of brain networks. Annals of the New York Academy of Sciences. 2011;1224(1):126-146. 